\title{
Minimally invasive treatment of lumbar spinal stenosis with a novel interspinous spacer
}

\author{
This article was published in the following Dove Press journal: \\ Clinical Interventions in Aging \\ 7 September 201 I \\ Number of times this article has been viewed
}

\author{
Shay Shabat' \\ Larry E Miller ${ }^{2,3}$ \\ Jon E Block ${ }^{3}$ \\ Reuven Gepstein' \\ 'Spinal Care Unit, Sapir Medical \\ Center, Kfar Saba, Israel; ${ }^{2}$ Miller \\ Scientific Consulting, Inc, Biltmore \\ Lake, NC, USA; 3Jon E Block, \\ $\mathrm{PhD}$, Inc, San Francisco, CA, USA
}

Correspondence: Jon E Block

Jon E Block, PhD, Inc,

2210 Jackson Street,

Suite 40 ISan Francisco, CA 94II5, USA

Tel +I 415 775-7947

Fax + I 415 928-0765

Email jonblock@jonblockphd.com
Purpose: To assess the safety and effectiveness of a novel, minimally invasive interspinous spacer in patients with moderate lumbar spinal stenosis (LSS).

Methods: A total of 53 patients (mean age, $70 \pm 11$ years; $45 \%$ female) with intermittent neurogenic claudication secondary to moderate LSS, confirmed on imaging studies, were treated with the Superion ${ }^{\circledR}$ Interspinous Spacer (VertiFlex, Inc, San Clemente, CA) and returned for follow-up visits at 6 weeks, 1 year, and 2 years. Study endpoints included axial and extremity pain severity with an 11-point numeric scale, Zurich Claudication Questionnaire (ZCQ), back function with the Oswestry Disability Index (ODI), health-related quality of life with the Physical Component Summary (PCS) and Mental Component Summary (MCS) scores from the SF-12, and adverse events.

Results: Axial and extremity pain each decreased 54\% (both $P<0.001$ ) over the 2-year follow-up period. ZCQ symptom severity scores improved 43\% $(P<0.001)$ and ZCQ physical function improved $44 \%(P<0.001)$ from pre-treatment to 2 years post-treatment. A statistically significant $50 \%$ improvement $(P<0.001)$ also was noted in back function. PCS and MCS each improved $40 \%$ (both $P<0.001$ ) from pre-treatment to 2 years. Clinical success rates at 2 years were $83 \%-89 \%$ for ZCQ subscores, $75 \%$ for ODI, $78 \%$ for PCS, and $80 \%$ for MCS. No device infection, implant breakage, migration, or pull-out was observed, although two (3.8\%) patients underwent explant with subsequent laminectomy.

Conclusion: Moderate LSS can be effectively treated with a minimally invasive interspinous spacer. This device is appropriate for select patients who have failed nonoperative treatment measures for LSS and meet strict anatomical criteria.

Keywords: Superion, axial pain, extremity pain

\section{Introduction}

Lumbar spinal stenosis (LSS) is a progressive degenerative narrowing of the central spinal canal and/or lateral neuroforamen that commonly leads to neurogenic claudication by compression of the spinal nerves and associated vasculature. ${ }^{1}$ LSS currently affects 1 million people in the United States and is the most common indication for spinal surgery in the elderly. ${ }^{2}$ While some patients with LSS are asymptomatic, most present with leg pain, numbness, and tingling that is exacerbated with ambulation and extension movements of the spinal column. Ultimately, these symptoms result in lower quality of life and impaired functional capacity. ${ }^{3}$

Despite the lack of convincing evidence to support their use, initial management of mild radicular symptoms focuses on nonsurgical options and includes activity modification, physical therapy, analgesic and anti-inflammatory medications, and 
epidural spinal injections. ${ }^{4}$ However, none of these therapies has demonstrated long-term effectiveness since they do not alter the course of disease progression. ${ }^{5,6}$ As the disease worsens to yield moderate symptoms, patients must tolerate progressively persistent pain and functional impairment since no additional treatment options are available. Ultimately, as the disease advances to produce chronic and severe symptoms, open spinal surgery such as decompressive laminectomy with or without fusion is often required to alleviate symptoms. ${ }^{7,8}$

Minimally invasive lumbar procedures represent a viable alternative that addresses the therapeutic gap for patients with moderate radicular symptoms. In particular, interspinous process decompression utilizes a spacer that is implanted between contiguous spinous processes to limit back extension at the symptomatic level, thereby improving patient symptoms. ${ }^{9}$ Potential advantages of this procedure versus other surgical procedures include lower neural injury risk, ability to intervene earlier in the disease process before symptoms become debilitating, and preservation of anatomical structures which allows the option of more invasive surgery in the future, should severe symptoms recur or further mechanical changes ensue. The X-STOP ${ }^{\circledR}$ Interspinous Process Decompression System (Medtronic, Inc, Minneapolis, MN) has been extensively studied in clinical trials, ${ }^{10-16}$ although reports with other spacers are less common. ${ }^{17-21}$ Despite overall favorable results with these devices in anatomically suitable patients, the clinical benefit of interspinous spacers is debatable given the paucity of available long-term data and the risk for devicerelated complications. ${ }^{22,23}$ This study was conducted to evaluate 2-year clinical outcomes in patients with moderate LSS who were treated with a novel, minimally invasive interspinous spacer.

\section{Materials and methods \\ Patients}

This single-arm prospective study enrolled 53 patients with moderate LSS between July 2007 and March 2008. All patients were treated with the Superion ${ }^{\circledR}$ Interspinous Spacer (VertiFlex, San Clemente, CA). Inclusion criteria for this study included: (1) diagnosis of moderate LSS, defined as $25 \%-50 \%$ reduction in lateral/central foramen diameter compared with adjacent levels and radiographic evidence (magnetic resonance imaging or computed tomography) of thecal sac and/or cauda equine compression, nerve root impingement by either osseous or nonosseous elements, and/or hypertrophic facets with canal encroachment;
(2) persistent leg, buttock, or groin pain, with or without back pain, that was relieved by lumbar flexion; and (3) unsuccessful nonoperative treatment for at least 3 months. Exclusion criteria included (1) axial back pain only, (2) grade II-V spondylolisthesis, (3) unremitting back pain in any spinal position, (4) active systemic disease that may affect the welfare of the patient, (5) vertebral osteoporosis or history of vertebral fracture, and (6) pregnant or lactating female. The procedures used in this clinical study were in accordance with the recommendations of the Helsinki Declaration, and each patient provided written informed consent before surgery.

\section{Intervention}

The Superion device is a single-piece, self-expanding titanium implant that is delivered via percutaneous access and deployed between the spinous processes of the symptomatic vertebral levels (Figure 1A and B). The minimally invasive procedure began with the patient lying prone on a radiolucent table with the lumbar spine in a neutral or slightly flexed position. Using fluoroscopic guidance or direct visualization, the symptomatic level was identified and a $12-15 \mathrm{~mm}$ midline incision was made. The supraspinous ligament was longitudinally dissected at the symptomatic level and was then dilated to ensure adequate room to maneuver within the interspinous space. A cannula was inserted over the dilator, and proper alignment and depth were ensured before dilator removal. Next, an interspinous gauge was inserted through the cannula to determine proper implant size selection. Final midline positioning was confirmed under fluoroscopy.

The appropriately sized spacer was delivered through the cannula using a device inserter that loaded the implant, inserted it into the interspinous space via the cannula, and then deployed the implant. Proper device placement was confirmed with fluoroscopy. Finally, the inserter and cannula were removed, and the incision was sutured in a standard fashion.
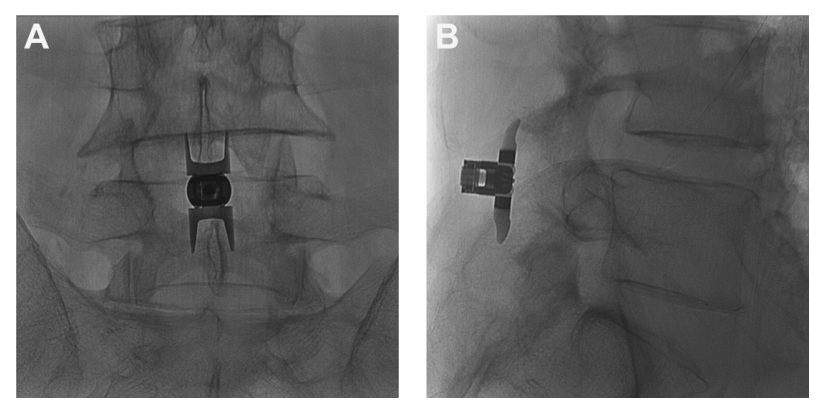

Figure I (A) Postero-anterior and (B) lateral radiographic images showing a properly placed Superion ${ }^{\circledR}$ Interspinous Spacer (VertiFlex, Inc, San Clemente, CA). 


\section{Outcomes}

Patients were assessed pre-treatment and then returned for follow-up visits at 6 weeks and at 1 and 2 years post-treatment. Axial and extremity pain severity was measured with an 11-point (0-10) numeric pain scale at pre-treatment and postoperatively only. The Zurich Claudication Questionnaire (ZCQ) was utilized to assess patient-reported measures of symptom severity, physical function, and patient satisfaction. ${ }^{14}$ Back-specific functional disability was measured with the Oswestry Disability Index (ODI) (version 2) on a $0 \%-100 \%$ scale. ${ }^{24}$ Health-related quality of life was assessed with the SF-12 ${ }^{\circledR}$, version 2, (Medical Outcomes Trust, Hanover, $\mathrm{NH}$ ) and Physical Component Summary (PCS) and Mental Component Summary (MCS) scores were recorded ${ }^{25}$ Safety was assessed by incidence of reported adverse events through the 2-year follow-up period.

\section{Data analysis}

Data were analyzed using Predictive Analytics Software, version 18 (SPSS, Inc, Chicago, IL). Patients included in this report had 2-year data available for at least one of the following variables: axial pain, extremity pain, ZCQ, ODI, PCS, and MCS. Continuous data were reported as mean \pm standard deviation, and categorical data were reported as frequencies and percentages. Longitudinal changes in patient outcomes were analyzed with repeated measures analysis of variance. Clinical success at each follow-up period was defined as $\mathrm{a} \geq 30 \%$ improvement in pain scores, ${ }^{26,27} \geq 0.5$ point improvement in ZCQ symptom severity and physical function, ${ }^{14} \mathrm{ZCQ}$ patient satisfaction score $\leq 2.5,{ }^{14} \geq 30 \%$ improvement in ODI, ${ }^{26,28} \geq 5.7$-point improvement in PCS, ${ }^{29}$ and $\geq 6.3$-point improvement in MCS. ${ }^{29}$

\section{Results}

Patient characteristics included mean age of $70 \pm 11$ years, $45 \%$ female, $98 \%$ (52 of 53) with single level disease, moderate disability, and severe back pain with a mean duration of $30 \pm 31$ months. Implant size ranged from 8 to $16 \mathrm{~mm}$ with the 11-13 mm devices accounting for two-thirds of implants (Table 1).

\section{Axial and extremity pain severity}

Axial pain decreased $54 \%(P<0.001)$ from $8.9 \pm 1.4$ at pretreatment to $4.1 \pm 3.4$ postoperatively (Figure $2 \mathrm{~A}$ ). At the postoperative follow-up, $73 \%$ ( 29 of 40 ) of patients achieved the clinical success threshold of a $\geq 30 \%$ improvement (Figure 2B). Similar improvements in extremity pain were realized with a mean improvement of $54 \%$ from $8.7 \pm 1.9$ at pre-treatment and
Table I Patient characteristics

\begin{tabular}{lll}
\hline Characteristic & N & Value \\
\hline Age, mean \pm SD, years & 53 & $70 \pm$ II \\
Female, $n(\%)$ & 53 & $24(45)$ \\
Previous spine operation, $n(\%)$ & 52 & $4(8)$ \\
Current smoker, $n(\%)$ & 53 & $4(8)$ \\
Duration of symptoms, mean \pm SD, months & 47 & $30 \pm 31$ \\
Axial pain score, mean \pm SD & 45 & $8.8 \pm 1.9$ \\
Extremity pain score, mean \pm SD & $4 I$ & $8.8 \pm 1.9$ \\
ZCQ symptom severity, mean \pm SD & 52 & $3.4 \pm 0.6$ \\
ZCQ physical function, mean \pm SD & 53 & $3.2 \pm 0.4$ \\
Oswestry Disability Index, mean \pm SD, \% & 52 & $57 \pm 14$ \\
Physical Component Summary score, mean \pm SD & 53 & $31 \pm 7$ \\
Mental Component Summary score, mean \pm SD & 53 & $33 \pm 8$ \\
\hline
\end{tabular}

Abbreviations: SD, standard deviation; ZCQ, Zurich Claudication Questionnaire

$4.1 \pm 3.2$ postoperatively $(P<0.001)$. Extremity pain clinical success was $74 \%$ (28 of 38 ) postoperatively.

\section{ZCQ}

ZCQ symptom severity scores improved $43 \%(P<0.001)$, and ZCQ physical function improved $44 \%(P<0.001)$ from
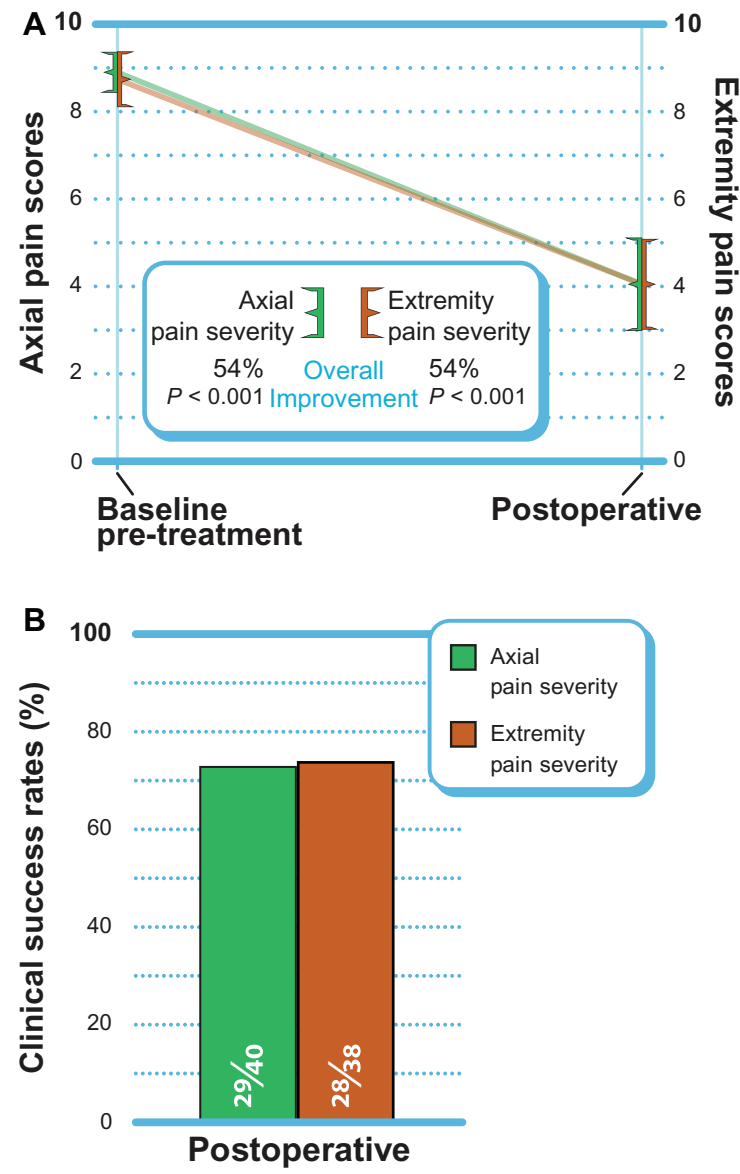

Figure 2 (A) Improvement in postoperative axial and extremity pain scores (mean $\pm 95 \%$ confidence interval). (B) Clinical success rates ( $\geq 30 \%$ improvement). 
pre-treatment to 2 years post-treatment (Figure 3A). The mean ZCQ patient satisfaction score was 1.9 at all follow-up visits. When using the standard criteria of an improvement of 0.5 points or greater to define 2-year clinical success, $83 \%$ (43 of 52) of patients achieved ZCQ symptom severity clinical success, and $89 \%$ (47 of 53) of patients achieved ZCQ physical function clinical success. Patient satisfaction clinical success (score $\leq 2.5$ ) at 2 years was $87 \%$ (46 of 53 ). The proportion of patients that achieved at least two of three clinical success criteria at 2 years was $87 \%$ (45 of 52) (Figure 3B).

\section{Back-specific functional impairment}

A statistically significant $50 \%$ improvement $(P<0.001)$ in back function was noted through 2 years post-treatment (Figure 4A). When using the standard criteria of an improvement of $30 \%$ or greater to define clinical success, $75 \%$ (39 of 52) of patients achieved ODI clinical success at 2 years (Figure 4B).

\section{Quality of life assessment}

PCS and MCS each improved 40\% $(P<0.001)$ from pre-treatment to 2 years (Figure 5A). Through 2 years, MCS clinical success was achieved in $80 \%$ (40 of 50) of patients,
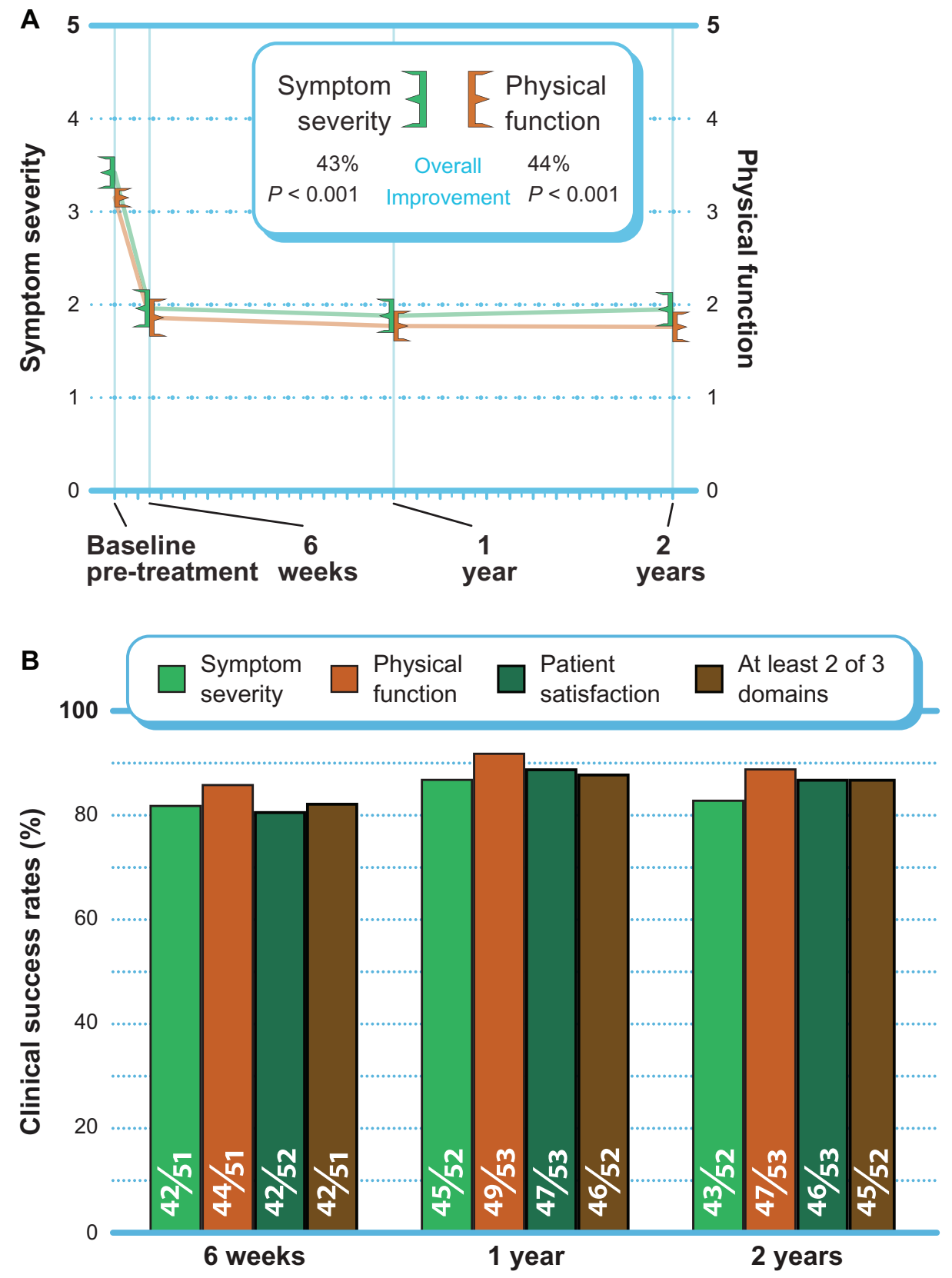

Figure 3 (A) Improvement in Zurich Claudication Questionnaire scores through 2 years post-treatment (mean $\pm 95 \%$ confidence interval). (B) Clinical success rates ( $\geq 0.5$ points symptom severity and physical function improvement, $\leq 2.5$ points patient satisfaction) through 2 years post-treatment. 

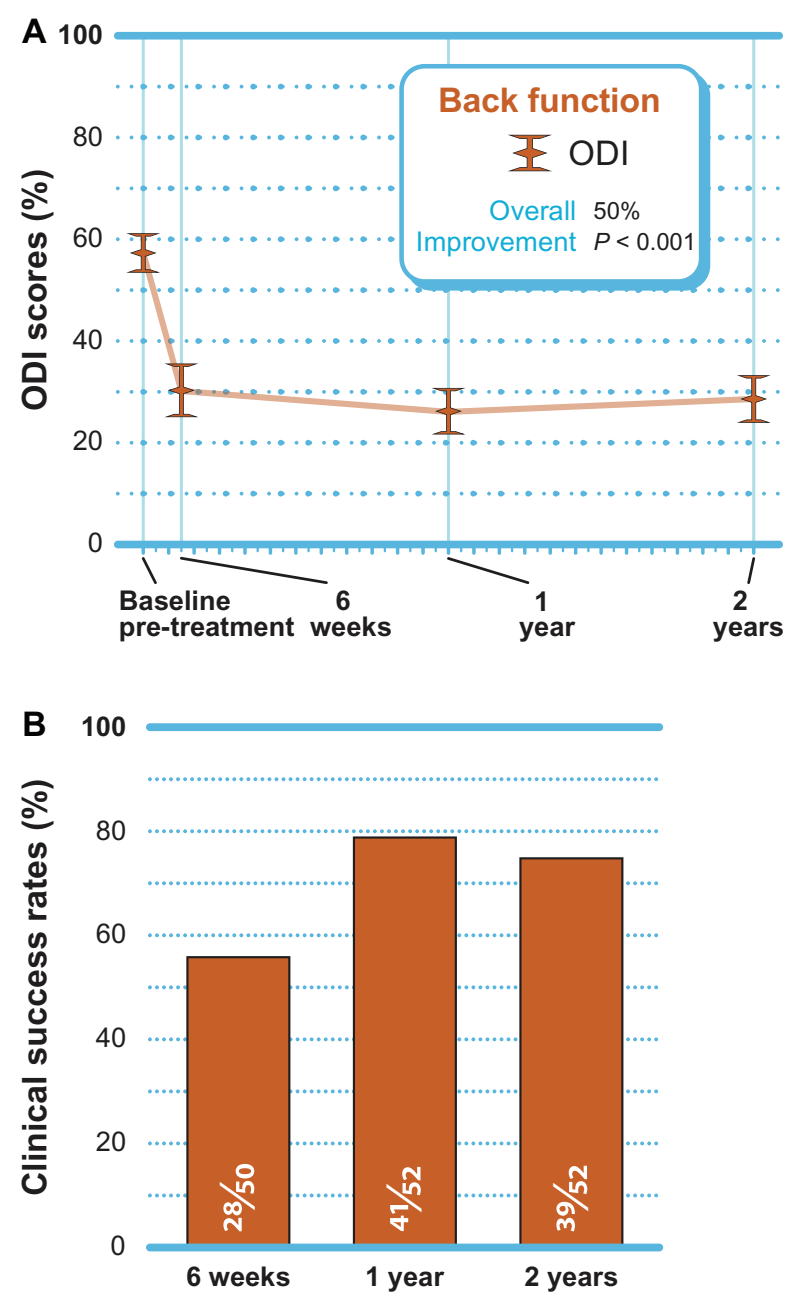

Figure 4 (A) Improvement in ODI scores through 2 years post-treatment (mean $\pm 95 \%$ confidence interval). (B) Clinical success rates ( $\geq 30 \%$ improvement) through 2 years post-treatment.

Abbreviation: ODI, Oswestry Disability Index.

while PCS clinical success was achieved in 78\% (39 of 50) of patients (Figure 5B).

\section{Adverse events}

No device infection, implant breakage, migration, or pull-out was observed through the 2-year follow-up visit. Two (3.8\%) patients underwent explant with subsequent laminectomy due to persistent radicular symptoms.

\section{Discussion}

The Superion Interspinous Spacer is a novel, minimally invasive device that offers excellent safety and effectiveness for the patient with intermittent neurogenic claudication secondary to moderate LSS based on the 2-year outcomes reported in the current study. All clinical markers of pain, function, and health-related quality of life improved by approximately $50 \%$ over the 2-year follow-up period.
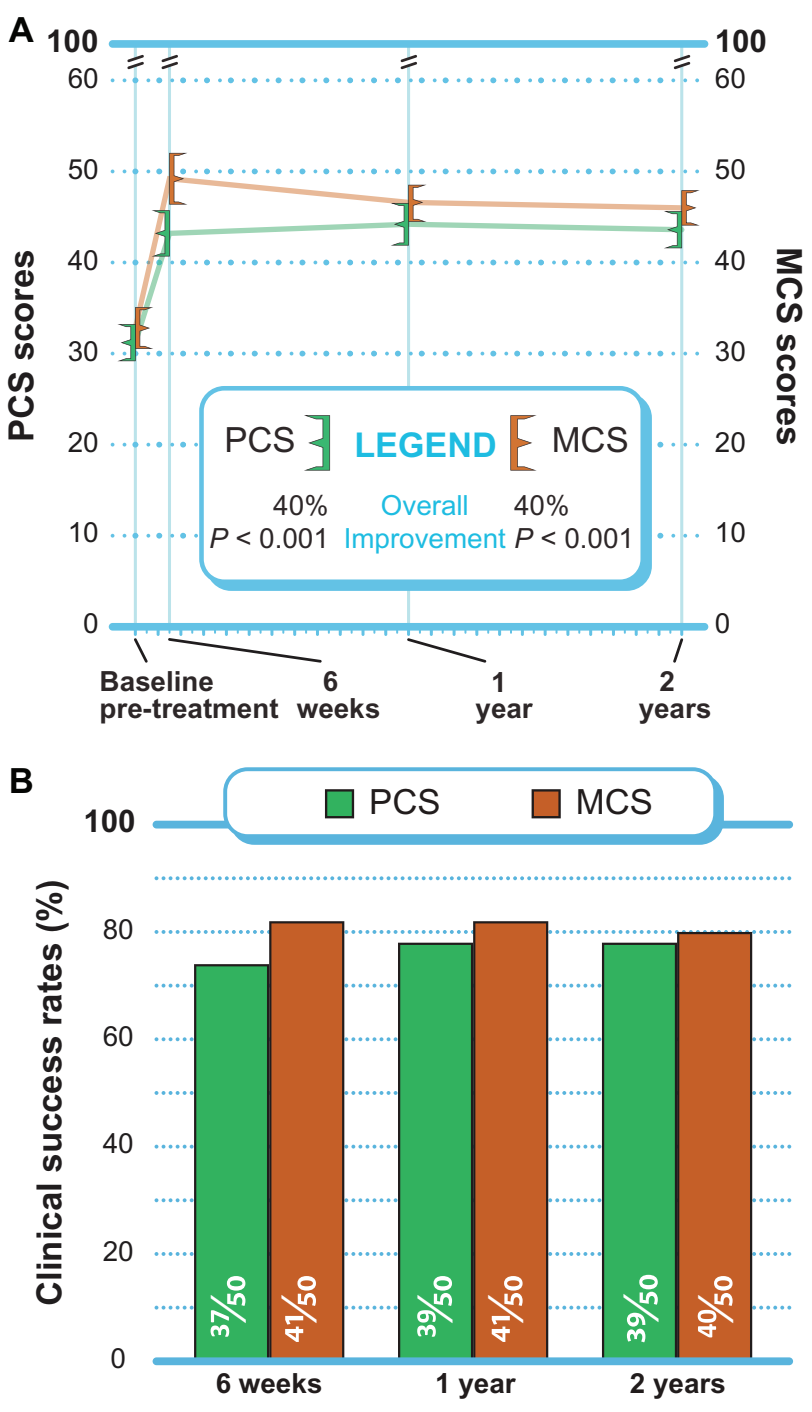

Figure 5 (A) Improvement in PCS and MCS scores through 2 years posttreatment (mean $\pm 95 \%$ confidence interval). (B) Success rates $(\geq 5.7$ points $P C S$ improvement, $\geq 6.3$ points MCS improvement) through 2 years post-treatment.

Abbreviations: MCS, Mental Component Summary; PCS, Physical Component Summary.

The outcomes observed in this study compare favorably to those reported with the X-STOP spacer with improvements of $44 \%$ for ZCQ physical function, $45 \%$ for ZCQ symptom severity, $36 \%$ for extremity pain, and $38 \%$ for ODI in these studies. ${ }^{12,16}$ Furthermore, the $3.8 \%$ reintervention rate in the current series approximates the $1.0 \%-4.6 \%$ reintervention rate reported in the largest X-STOP trials. ${ }^{12,16}$

The safety and effectiveness of the Superion device also appears to be similar to that of laminectomy. Success rates of $74 \%-89 \%$ were observed, depending on the outcome, in the current series. Overall success rates with laminectomy range from $26 \%$ to $100 \% .^{8,30-32}$ No device-complications were observed in the current series, although persistent radicular symptoms requiring device explant were reported 
in two $(3.8 \%)$ patients. Common complications of laminectomy are dural tear $(6 \%)$, infection (3\%), and deep vein thrombosis $(3 \%){ }^{8}$

Despite the low incidence of complications in this series, several concerns have been raised regarding use of interspinous spacers including device subsidence, spinous process fracture, treated segment destabilization, and adjacent segment degeneration. Although concern for device subsidence has been acknowledged with interspinous spacers, no known study has reported this complication to date. Spinous process fracture has been noted in $0 \%-6 \%$ of patients treated with interspinous spacers who were followed with plain radiographs, ${ }^{16,33,34}$ although one study reported a $29 \%$ fracture incidence with computed tomographic imaging. ${ }^{35}$ Low lumbar bone mineral density has been suggested as a potential risk factor for device fracture, and severe osteoporosis is a common exclusion criterion for these devices. ${ }^{35}$ Destabilization of the treated segment is purported as a potential risk of interspinous spacer treatment. Biomechanical studies have yielded mixed conclusions on the effect of an implanted interspinous spacer on segmental range of motion, ${ }^{36,37}$ and no definitive evidence from human trials currently exists. Despite concern for adjacent segment degeneration with long-term interspinous spacer implant, no biomechanical or human study has demonstrated that an interspinous spacer has deleterious effects on adjacent levels. ${ }^{36,38,39}$ Overall, complications with interspinous spacers are uncommon and seem to be primarily attributable to improper patient selection. ${ }^{34}$

The appropriateness of patients with low-grade slip for interspinous spacer treatment is debatable. The study of Verhoof and colleagues ${ }^{40}$ investigated interspinous spacer use in 12 patients ( 9 with grade I slip and 2 with grade II slip) and reported a $58 \%$ reintervention rate within 2 years. In the largest study in interspinous spacer use in patients with lowgrade slip, patients treated with interspinous spacer $(n=42)$ had a similar reintervention rate $(12 \%)$ as subjects treated nonoperatively $(\mathrm{n}=33) \cdot{ }^{33}$ Implantation of an interspinous spacer prevents motion at the implanted level ${ }^{41}$ and results in no progression of spondylolisthesis over time. ${ }^{33}$ Most studies of interspinous spacers allow enrolment of patients with grade I slip, and no compelling evidence exists to exclude these patients from treatment consideration. ${ }^{23,34}$

Patient selection is critical to ensure a high probability of treatment success with an interspinous spacer. Patients must have confirmatory imaging evidence of LSS, relief of symptoms during lumbar flexion, adequate vertebral bone mineral density, and must be nonresponsive to conservative care efforts in order to realize maximum benefit from this therapy. The favorable safety profile observed with this interspinous spacer for treatment of LSS is attributed not only to careful patient selection but also because resection of the posterior spinal elements was not required, and therefore, motion of the lumbar spine is preserved.

The primary limitation of this study was the lack of a concurrent control group, which may have introduced bias into the interpretation of study outcomes. However, the magnitude of benefit with the interspinous spacer was so dramatic that nonspecific study effects such as placebo could not reasonably account for all of the noted clinical improvement.

Interspinous spacer implant with the Superion device is a safe and effective treatment option for carefully selected patients with moderate LSS who are unresponsive to conservative care but are not yet eligible candidates for traditional spinal surgery such as laminectomy.

\section{Acknowledgments}

The authors thank Mr Randy Asher for assistance with graphical illustrations. Vertiflex, Inc, (San Clemente, CA) provided financial support for development of this manuscript.

\section{Disclosure}

The authors have no conflicts of interest in this work.

\section{References}

1. Arbit E, Pannullo S. Lumbar stenosis: a clinical review. Clin Orthop Relat Res. 2001;384:137-143.

2. Atlas SJ, Keller RB, Robson D, Deyo RA, Singer DE. Surgical and nonsurgical management of lumbar spinal stenosis: four-year outcomes from the maine lumbar spine study. Spine (Phila Pa 1976). 2000;25(5): 556-562.

3. Lin SI, Lin RM, Huang LW. Disability in patients with degenerative lumbar spinal stenosis. Arch Phys Med Rehabil. 2006;87(9):1250-1256.

4. Atlas SJ, Delitto A. Spinal stenosis: surgical versus nonsurgical treatment. Clin Orthop Relat Res. 2006;443:198-207.

5. Markman JD, Gaud KG. Lumbar spinal stenosis in older adults: current understanding and future directions. Clin Geriatr Med. 2008;24(2): 369-388, viii.

6. Simotas AC. Nonoperative treatment for lumbar spinal stenosis. Clin Orthop Relat Res. 2001;384:153-161.

7. Fritz JM, Delitto A, Welch WC, Erhard RE. Lumbar spinal stenosis: a review of current concepts in evaluation, management, and outcome measurements. Arch Phys Med Rehabil. 1998;79(6):700-708.

8. Turner JA, Ersek M, Herron L, Deyo R. Surgery for lumbar spinal stenosis. Attempted meta-analysis of the literature. Spine (Phila Pa 1976). 1992;17(1):1-8.

9. Bono CM, Vaccaro AR. Interspinous process devices in the lumbar spine. J Spinal Disord Tech. 2007;20(3):255-261.

10. Hsu KY, Zucherman JF, Hartjen CA, et al. Quality of life of lumbar stenosis-treated patients in whom the X STOP interspinous device was implanted. J Neurosurg Spine. 2006;5(6):500-507. 
11. Kondrashov DG, Hannibal M, Hsu KY, Zucherman JF. Interspinous process decompression with the X-STOP device for lumbar spinal stenosis: a 4-year follow-up study. J Spinal Disord Tech. 2006;19(5): 323-327.

12. Kuchta J, Sobottke R, Eysel P, Simons P. Two-year results of interspinous spacer (X-Stop) implantation in 175 patients with neurologic intermittent claudication due to lumbar spinal stenosis. Eur Spine J. 2009;18(6):823-829.

13. Lee J, Hida K, Seki T, Iwasaki Y, Minoru A. An interspinous process distractor (X STOP) for lumbar spinal stenosis in elderly patients: preliminary experiences in 10 consecutive cases. $J$ Spinal Disord Tech. 2004;17(1):72-77; discussion 78.

14. Siddiqui M, Smith FW, Wardlaw D. One-year results of X Stop interspinous implant for the treatment of lumbar spinal stenosis. Spine (Phila Pa 1976). 2007;32(12):1345-1348.

15. Zucherman JF, Hsu KY, Hartjen CA, et al. A prospective randomized multi-center study for the treatment of lumbar spinal stenosis with the X STOP interspinous implant: 1-year results. Eur Spine J. 2004;13(1): $22-31$.

16. Zucherman JF, Hsu KY, Hartjen CA, et al. A multicenter, prospective, randomized trial evaluating the $\mathrm{X}$ STOP interspinous process decompression system for the treatment of neurogenic intermittent claudication: two-year follow-up results. Spine (Phila Pa 1976). 2005; 30(12):1351-1358.

17. Buric J, Pulidori M. Long-term reduction in pain and disability after surgery with the interspinous device for intervertebral assisted motion (DIAM) spinal stabilization system in patients with low back pain: 4-year follow-up from a longitudinal prospective case series. Eur Spine J. 2011;20(8):1304-1311.

18. Buric J, Pulidori M, Sinan T, Mehraj S. DIAM device for low back pain in degenerative disc disease : 24 months follow-up. Acta Neurochir Suppl. 2011;108:177-182.

19. Nardi P, Cabezas D, Rea G, Pettorini BL. Aperius PercLID stand alone interspinous system for the treatment of degenerative lumbar stenosis: experience on 152 cases. J Spinal Disord Tech. 2010;23(3):203-207.

20. Sobottke R, Schluter-Brust K, Kaulhausen T, et al. Interspinous implants (X Stop, Wallis, Diam) for the treatment of LSS: is there a correlation between radiological parameters and clinical outcome? Eur Spine J. 2009;18(10):1494-1503.

21. Fabrizi AP, Maina R, Schiabello L. Interspinous spacers in the treatment of degenerative lumbar spinal disease: our experience with DIAM and Aperius devices. Eur Spine J. 2011;20 Suppl 1:S20-S26.

22. Kabir SM, Gupta SR, Casey AT. Lumbar interspinous spacers: a systematic review of clinical and biomechanical evidence. Spine (Phila Pa 1976). 2010;35(25):E1499-E1506.

23. Kim DH, Albert TJ. Interspinous process spacers. J Am Acad Orthop Surg. 2007;15(4):200-207.

24. Fairbank JC, Pynsent PB. The Oswestry Disability Index. Spine (Phila Pa 1976). 2000;25(22):2940-2952; discussion 2952.

25. Jenkinson $C$, Layte $R$, Jenkinson $D$, et al. A shorter form health survey: can the SF-12 replicate results from the SF-36 in longitudinal studies? J Public Health Med. 1997;19(2):179-186.

26. Ostelo RW, Deyo RA, Stratford P, et al. Interpreting change scores for pain and functional status in low back pain: towards international consensus regarding minimal important change. Spine (Phila Pa 1976). 2008;33(1):90-94.
27. Hagg O, Fritzell P, Nordwall A. The clinical importance of changes in outcome scores after treatment for chronic low back pain. Eur Spine $J$. 2003;12(1):12-20.

28. Zigler J, Delamarter R, Spivak JM, et al. Results of the prospective, randomized, multicenter Food and Drug Administration investigational device exemption study of the ProDisc-L total disc replacement versus circumferential fusion for the treatment of 1-level degenerative disc disease. Spine (Phila Pa 1976). 2007;32(11):1155-1162; discussion 1163

29. Ware JE Jr. SF-36 health survey update. Spine (Phila Pa 1976). 2000; 25(24):3130-3139.

30. Dunlop RB, Adams MA, Hutton WC. Disc space narrowing and the lumbar facet joints. J Bone Joint Surg Br. 1984;66(5):706-710.

31. Johnsson KE, Rosen I, Uden A. The natural course of lumbar spinal stenosis. Clin Orthop Relat Res. 1992;279:82-86.

32. Katz JN, Lipson SJ, Chang LC, Levine SA, Fossel AH, Liang MH Seven- to 10-year outcome of decompressive surgery for degenerative lumbar spinal stenosis. Spine (Phila Pa 1976). 1996;21(1):92-98.

33. Anderson PA, Tribus CB, Kitchel SH. Treatment of neurogenic claudication by interspinous decompression: application of the $\mathrm{X}$ STOP device in patients with lumbar degenerative spondylolisthesis. J Neurosurg Spine. 2006;4(6):463-471.

34. Barbagallo GM, Olindo G, Corbino L, Albanese V. Analysis of complications in patients treated with the X-Stop Interspinous Process Decompression System: proposal for a novel anatomic scoring system for patient selection and review of the literature. Neurosurgery. 2009; 65(1):111-119; discussion 119-120.

35. Kim DH, Tantorski M, Shaw J, et al. Occult spinous process fractures associated with interspinous process spacers. Spine (Phila Pa 1976). 2011;36(16):E1080-E1085.

36. Lindsey DP, Swanson KE, Fuchs P, Hsu KY, Zucherman JF, Yerby SA. The effects of an interspinous implant on the kinematics of the instrumented and adjacent levels in the lumbar spine. Spine (Phila Pa 1976). 2003;28(19):2192-2197.

37. Fuchs PD, Lindsey DP, Hsu KY, Zucherman JF, Yerby SA. The use of an interspinous implant in conjunction with a graded facetectomy procedure. Spine (Phila Pa 1976). 2005;30(11):1266-1272; discussion 1273-1264.

38. Wiseman CM, Lindsey DP, Fredrick AD, Yerby SA. The effect of an interspinous process implant on facet loading during extension. Spine (Phila Pa 1976). 2005;30(8):903-907.

39. Swanson KE, Lindsey DP, Hsu KY, Zucherman JF, Yerby SA. The effects of an interspinous implant on intervertebral disc pressures. Spine (Phila Pa 1976). 2003;28(1):26-32.

40. Verhoof OJ, Bron JL, Wapstra FH, van Royen BJ. High failure rate of the interspinous distraction device (X-Stop) for the treatment of lumbar spinal stenosis caused by degenerative spondylolisthesis. Eur Spine $J$. 2008;17(2):188-192.

41. Goyal A, Goel VK, Mehta A, Dick D, Chinthakunta SR, Ferrara L. Cyclic loads do not compromise functionality of the interspinous spacer or cause damage to the spinal segment: an in vitro analysis. J Long Term Eff Med Implants. 2008;18(4):289-302.
Clinical Interventions in Aging

\section{Publish your work in this journal}

Clinical Interventions in Aging is an international, peer-reviewed journal focusing on evidence-based reports on the value or lack thereof of treatments intended to prevent or delay the onset of maladaptive correlates of aging in human beings. This journal is indexed on PubMed Central, MedLine, the American Chemical Society's 'Chemical Abstracts Ser-

\section{Dovepress}

vice' (CAS), Scopus and the Elsevier Bibliographic databases. The manuscript management system is completely online and includes a very quick and fair peer-review system, which is all easy to use. Visit http://www.dovepress.com/testimonials.php to read real quotes from published authors. 